\title{
Baseline and endline findings of Filles Eveillées ('Girls awakened'): A pilot program for migrant adolescent girls in domestic service. Cohort 1 (2011-2012), Bobo-Dioulasso
}

Sarah Engebretsen

Population Council

Follow this and additional works at: https://knowledgecommons.popcouncil.org/departments_sbsr-pgy

Part of the Demography, Population, and Ecology Commons, Family, Life Course, and Society Commons, Gender and Sexuality Commons, International Public Health Commons, Medicine and Health Commons, Migration Studies Commons, and the Women's Health Commons How does access to this work benefit you? Let us know!

\section{Recommended Citation}

Engebretsen, Sarah. 2012. "Baseline and endline findings of Filles Eveillées ('Girls awakened'): A pilot program for migrant adolescent girls in domestic service. Cohort 1 (2011-2012), Bobo-Dioulasso." Ouagadougou: Population Council. 
BASELINE AND ENDLINE

FINDINGS OF FILLES EVEILLÉES

(GIRLS AWAKENED)

A PILOT PROGRAM FOR MIGRANT ADOLESCENT GIRLS IN DOMESTIC SERVICE

COHORT 1 (2011-2012), BOBO DIOULASSO

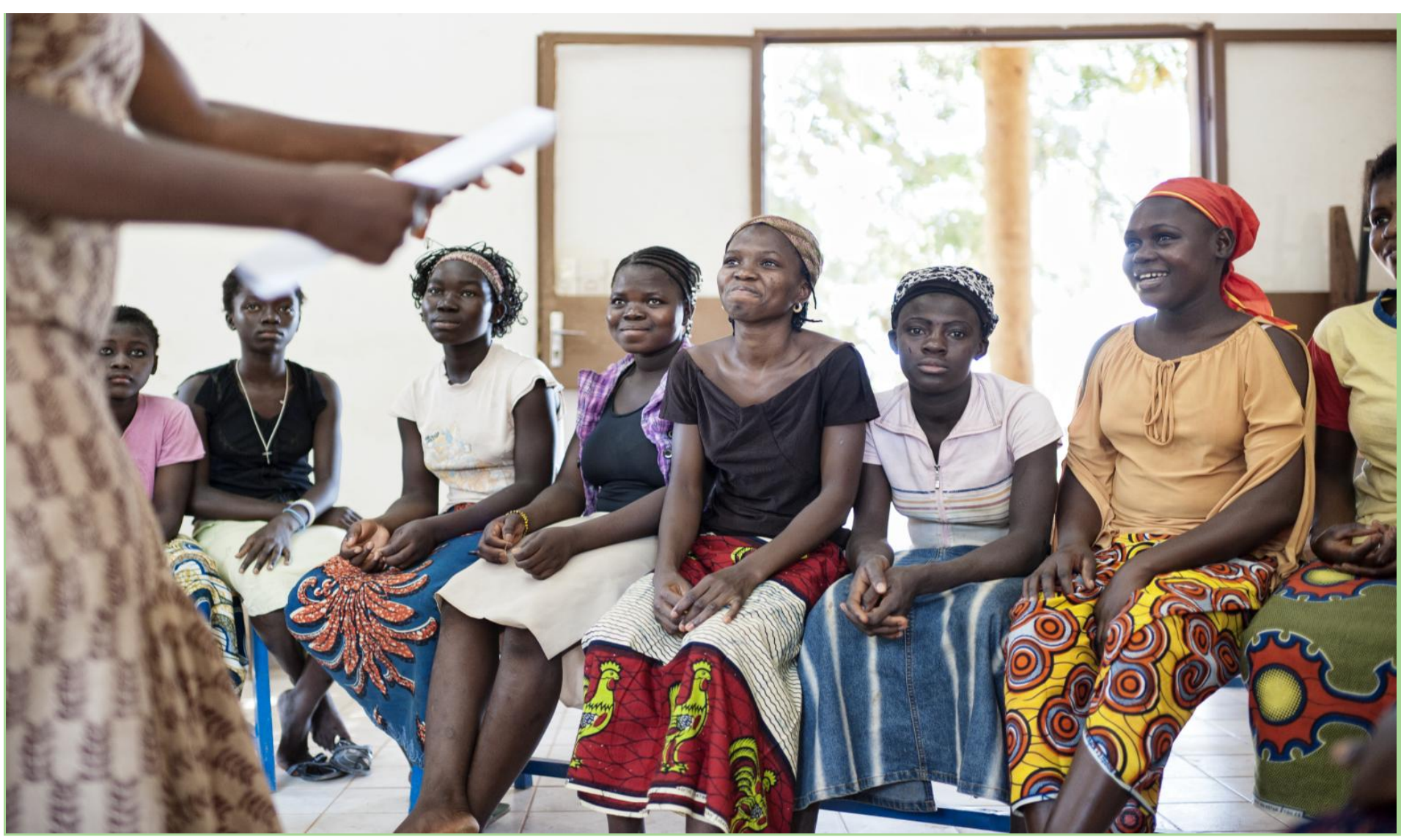




\section{(P) Population Council}

The Population Council confronts critical health and development issues-from stopping the spread of HIV to improving reproductive health and ensuring that young people lead full and productive lives. Through biomedical, social science, and public health research in 50 countries, we work with our partners to deliver solutions that lead to more effective policies, programs, and technologies that improve lives around the world. Established in 1952 and headquartered in New York, the Council is a nongovernmental, nonprofit organization governed by an international board of trustees.

Population Council

One Dag Hammarskjold Plaza

New York, NY 10017

www.popcouncil.org

Suggested citation: Sarah Engebretsen. 2012. "Baseline and Endline Findings of Filles Éveillées (Girls Awakened): A Pilot Program for Migrant Adolescent Girls in Domestic Service. Cohort 1 (2011-2012), Bobo Dioulasso": New York: Population Council.

Cover photo by Ollivier Girard, courtesy of the Population Council

(c) 2012 The Population Council, Inc. 


\section{TABLE OF CONTENTS}

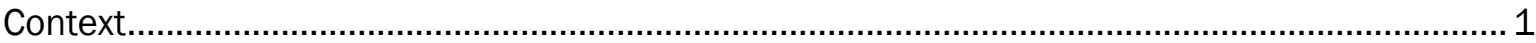

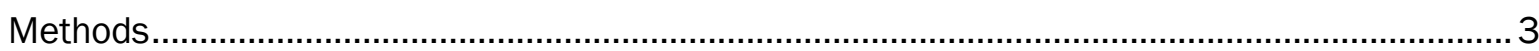

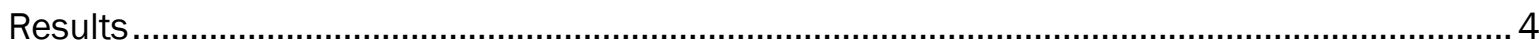

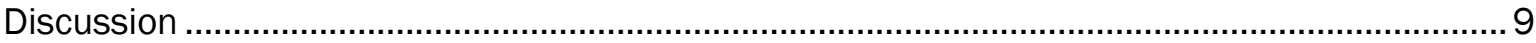


Burkina Faso has the tenth youngest population in the world, with 45.2 percent of the population below the age of 15.1 Young people in Burkina Faso have few economic opportunities, particularly in rural areas. This is especially true for adolescent girls, who typically have very little schooling and other preparation to take up work. This paucity of economic opportunities in rural areas drives migration-both internal and international-to urban areas in search of work. For many girls, the chance to work in an urban area in domestic service is an opportunity to earn money, often to purchase supplies in preparation for marriage. On their own, girls are physically and economically vulnerable and many of them are at heightened risk for gender-based violence. In a rush to begin earning money, girls may settle into unsafe or improperly remunerated working situations.

\section{Formative Research Findings}

With funding from the Jacobs Foundation, the Population Council conducted formative research in 2010 to better understand the situation of migrant adolescent girls in domestic service in urban Burkina Faso. This formative research included a desk review of literature on adolescent domestic workers, focus group discussions with adolescent domestic workers, and in-depth interviews with employers, logeurs, and nongovernmental organizations intervening with adolescent domestic workers and/or migrant girls. Findings revealed that girls migrate away from home due to a lack of opportunity. Once they arrive in the city, these girls typically live with their employers and work long and arduous days. This leaves them with little time for schooling, building social networks, and developing skills necessary for adulthood.

The formative research also showed that step migration-or migration to a smaller city and then onto the capital city-is common among adolescent girls. Moreover, girls' migration is typically seasonal; girls live and work in cities during the dry season and then return home each year to help out with agricultural tasks during the rainy season. The formative research revealed that the majority of programs designed for this population intervene after something has gone wrong rather than building girls' protective assets; focus on teaching girls about their rights rather than imparting skills; are not designed around logical age segments; and focus on inputs (i.e., number of radio messages delivered) rather than measurable change at the level of the girl.

\section{The Filles Éveillées Program}

In response to these findings, the Population Council designed an eight-month, 30-session safe spaces intervention for migrant adolescent domestic workers in urban Burkina Faso. Filles Éveillées (Girls Awakened) aims to increase social capital, build adolescent girls' skills in health including sexual and reproductive health, life skills, and financial capabilities, and link girls to services. By providing girls with a safe space, access to peers, and a female mentor, this program

\footnotetext{
1 Population Reference Bureau. (2011). World Population Data Sheet. Accessed July 22, 2012 via: http://www.prb.org/pdf11/2011population-data-sheet eng.pdf
} 
seeks to increase domestic workers' opportunities and reduce their vulnerabilities. The 20112013 pilot program has two program cycles. The 2011-2012 cohort was conducted in Bobo Dioulasso-specifically in the neighborhoods of Diarradougou in sector 2; Koko, which is divided between sectors 4, 15, and 16; Sikassocira in sector 8; Accart-Ville, which is divided between sectors 9 and 10; Sarfalao in sector 17; and Lafiabougou in sector 20. The 2012-2013 cohort will be drawn from Ouagadougou as well as Bobo Dioulasso.

Recruitment: Female mentors were recruited from the selection communities following announcements made by local leaders and public criers. Applications were submitted to the implementing organization, Association Tié. Short-listed candidates were interviewed, and mentors and alternates were selected by a committee of three people from the implementing organization. Mentors were well-known and well-respected in their communities, 20-30 years old, literate, able to speak Dioula, and had achieved at least a few years of secondary education. Before beginning to recruit participants, mentors in Bobo were given a three-day training by Association Tié. The training covered the objectives of the program, requirements for home visits, community meetings, evaluation tools, and a detailed review of each lesson in the curriculum. Following training and subsequent community awareness sessions, mentors went door to door in the selected communities to identify eligible girls and to sensitize the community regarding the Filles Éveillées program. Migrant girls 11-162 years old who were currently employed as domestic workers in one of the selected project sites were invited to participate in the program. Their employers or guardians were asked for permission. Both participants and employers were asked to sign the program permission form and consent to girls' participation in program surveys. A total of 180 girls were recruited for the program's first cohort.

Participation in girls' groups: Due to the time constraints of this target population, groups met once a week on Sundays for about two hours. Groups were held in empty classrooms in local schools, municipal buildings, local NGOs, and a semi-enclosed courtyard. Sessions were designed to be interactive and utilized group discussions, personal stories, exercises, and roleplays to teach girls specific competencies in life skills, health and hygiene, sexual and reproductive health, and financial education. All groups completed the 30 sessions, despite the fact that some groups had less than eight months to do so (please see footnote on next page). On average, participants in Filles Éveillées attended 22 out of 30 sessions. Seventy-two percent attended at least 20 of the sessions, and one in five girls attended all 30 sessions.

The pre- and post-test design was used to evaluate the Filles Éveillées program by assessing improvements in participating girls' social capital as well as knowledge, attitudes, and behaviors in key program areas. This report explores the baseline and endline findings from adolescent girls ages 11-16 who participated in Cohort 1 of the Filles Éveillées program in Bobo Dioulasso from 2011-2012.

\footnotetext{
2 The target age range for this program is $11-18$, but this report highlights only the findings from Cohort 1 in Bobo Dioulasso, where eligibility criteria were 11-16 years old based on findings from the formative research. The 2012-2013 cohort in Ouagadougou will include girls 15-18 years old.
} 


\section{Instrument Design and Data Collection}

The baseline and endline instruments were co-designed by staff from the Population Council's Burkina Faso office and headquarters. The study instruments utilized questions that Population Council has used in adolescent surveys with similar populations in other sub-Saharan African countries. The questions were then adapted to the Burkina context and refined to assess migrant and domestic worker specific information. The survey instrument was largely close-ended. Data were collected on socio-demographic characteristics, life skills and social capital, health and hygiene, sexual and reproductive health, financial capabilities, and gender. The baseline and endline surveys were nearly identical; the endline questionnaire included questions on attitudes toward the program.

The pre-test was conducted in early November 2011 in Diarradougou, Koko, and Accart-Ville and in early 2012 in Sikassocira, Sarfalao, and Lafiabougou. ${ }^{3}$ Shortly after completion of the pre-test, the Filles Éveillées program began. A post-test survey was conducted in late June/early July 2012, after program completion.

Given the somewhat sensitive nature of the survey topics, female interviewers administered the surveys. Minimum qualifications included having a university education; ability to speak Dioula, the local language in Bobo Dioulasso; experience with quantitative data collection; sensitivity to questions related to vulnerable adolescents and gender; and ability to work as a member of a team. The program used interviewers who were relatively young ( 24 to 26 years old) to put adolescent girls at ease in answering questions. Interviewers participated in a comprehensive training on the goals of the program, important interview techniques and role-plays, translating the questionnaire into the local language ${ }^{4}$ the need for privacy during data collection, and the importance of confidentiality. Following this training, baseline interviewers pre-tested the questionnaires in periphery neighborhoods in order to refine any questions or response categories that eluded respondents. A few slight modifications were made to the questionnaire before administering it with the target population. Baseline interviewers were retained for endline data collection wherever possible to ensure effective data collection for the endline survey.

Data collection was supervised by a consultant with experience working with the Institut Supérieur des Sciences de la Population at the University of Ouagadougou. This consultant also facilitated the interviewer training, data entry, data cleaning, and variable recoding. Interviews were conducted in private away from employers and other household members to put the respondent at ease in answering questions. Interviews lasted between 45 minutes and one hour. Given the busy schedules of domestic workers, interviewers had to be flexible about scheduling interviews at a time that was most convenient for the girl.

\footnotetext{
3 Cohort 1 was initially designed to take place in Bobo Dioulasso and Ouagadougou. However, challenges with a subgrantee in Ouagadougou resulted in a revised plan where additional groups of girls would be recruited in Bobo Dioulasso, which explains why some groups started later than others.

4 The questionnaires were written in French and administered in Dioula; in cases where the girls did not speak Dioula, the questionnaire was administered in Dagara.
} 
Completed questionnaires were checked by supervisors for data quality and completeness. Data were entered into SPHINX survey software, which is known for its ability to control for errors made during data collection. Nevertheless, errors are inevitable; cleaning of baseline and endline data was done over a period of 2-3 weeks, and coherence tests were run in STATA and SPSS. Password-protected data were sent from the Population Council's Burkina Faso office to headquarters, where they were analyzed using SPSS 17 with inputs from the Burkina Faso team.

\section{RESULTS}

\section{Sample Characteristics}

A total of 180 respondents completed the baseline survey, 90 in the November 2011 round of data collection in Diarradougou, Koko, and Accart-Ville, and 90 in early 2012 in Sikassocira, Sarfalao, and Lafiabougou. The endline sample included a total of 129 girls, with a disproportionate share of girls in Sikassocira not participating in the endline survey. This loss-tofollow-up was attributed to the uncharacteristically early arrival of the 2012 rainy season, which prompted many girls to return to their villages to provide help with agricultural tasks.

Seven of the 180 baseline respondents reported being over the target age range of 11-16 years old and were accordingly excluded from the baseline analysis and from the program. ${ }^{5}$ About onequarter of respondents were considered younger adolescents (11-13). Six percent reported not knowing their age at baseline, which is not uncommon for the target population; they were retained in the analysis and in the program as they reported being within the program's target age range during recruitment and appeared to meet eligibility criteria. Of note, almost one-third of girls at baseline reported not having personal documents such as an identity card with a birthdate. By endline, only $4 \%$ reported not knowing their age, which may indicate their increased sense of self-awareness.

The sample population is highly mobile, and internal migration is far more common than international among Filles Éveillées participants. Ninety-six percent of participants reported being born in Burkina, and the remaining girls were born in neighboring Mali and Côte d'Ivoire. When interviewed at baseline, 61\% reported living in their current neighborhood for less than one year. Four-fifths of girls reported moving to the city for economic and employment reasons. More than three-quarters of girls lived with their employers. The highest level of education attained and literacy in French improved from the pre-test to the post-test as shown in Table 1, likely due to the optional arms for participation in cours du soir, which 59 girls took advantage of in Cohort 1.

\footnotetext{
5 These seven vacancies were opened to other girls in the program for a total of 180 participants, though baseline data are unavailable for those girls who joined the program shortly after it officially launched.
} 
TABLE 1: Percent distribution of surveyed girls in Filles Éveillées program by selected characteristics, according to time of survey

\begin{tabular}{|l|l|l|}
\hline & Baseline (N=173) & Endline (N=129) \\
\hline Highest level of education attained & & \\
\hline Primary & $34 \%$ & $45 \%$ \\
\hline Secondary & $3 \%$ & $4 \%$ \\
\hline $\begin{array}{l}\text { Other/outside of the formal system } \\
\text { (i.e., franco-arabe or literacy) }\end{array}$ & $6 \%$ & $5 \%$ \\
\hline Never been to school & $57 \%$ & $46 \%$ \\
\hline Literacy in French* & & \\
\hline Reads easily & $8 \%$ & $16 \%$ \\
\hline Reads with difficulty & $9 \%$ & $9 \%$ \\
\hline Cannot read & $83 \%$ & $74 \%$ \\
\hline
\end{tabular}

*Self-reported literacy was confirmed by asking participants to read aloud a simple sentence ("Je suis contente de participer au programme").

\section{Social Capital and Life Skills}

Filles Éveillées provided girls with opportunities to expand their social networks by participating in same-sex groups led by adult female mentors. Baseline findings indicate that migrant adolescent girls in domestic service are highly socially isolated; 95\% reported not being part of any social groups. By endline, girls did not report any additional affiliations with social groups (such as sport, study, dance, and religious groups), suggesting that Filles Éveillées was their sole opportunity for formal group affiliation. Positive changes were observed from baseline to endline in participants' reported social capital as measured by the questions "has a safe place to meet friends" (56\% vs. $63 \%)$, "has someone to borrow money from in an emergency" (62\% vs. $72 \%)$, and "has people to talk to for advice" (91\% vs. 98\%). At endline, $97 \%$ of girls agreed with the statement that they had more female friends now as a result of the program. Program mentors were also part of participants' expanded social networks; $100 \%$ of the endline sample reported being able to talk to their mentors if a problem arose in their lives. In addition to expanding social networks, the program was designed to improve girls' ability to express themselves, and $99 \%$ of endline respondents reported that after participation in the program, they felt at ease in resolving conflicts with others. The program was also designed to build self-confidence, and $96 \%$ of girls at endline agreed with the statement that they now had more confidence in expressing themselves as a result of the program. Figure 1 shows changes reported over time in self-confidence and ability to express oneself. 
FIGURE 1: Percent distribution of surveyed girls in Filles Éveillées program by self-confidence measures, according to time of survey

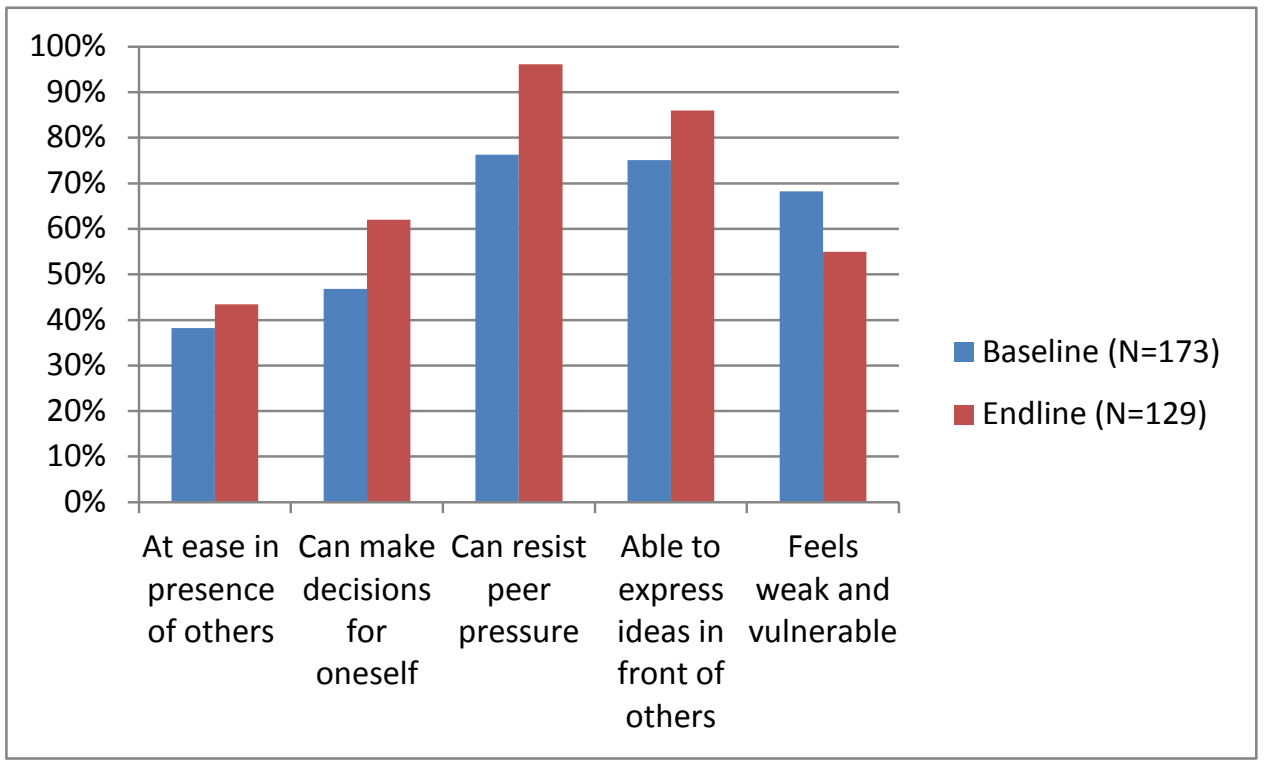

\section{Health and Hygiene}

Filles Éveillées provided program participants with opportunities to learn about important topics related to health and hygiene. The program also gave girls skills to manage their own health and explored attitudes around health-seeking behavior. About half of girls reported visiting a health center in case of illness. Reasons cited for not visiting health centers in cases of illness included not having enough money, not feeling sick enough to seek care, and beliefs that health centers were reserved exclusively for well-educated people. When asked why some girls their age visit health centers, only $12 \%$ of baseline respondents knew that health centers can provide health information, but this increased to $50 \%$ at endline.

Girls' attitudes toward health centers improved over time; at baseline, 86\% agreed that local health facilities were girl-friendly compared to $97 \%$ at endline. Positive changes were observed in awareness of steps to be taken to improve one's health; at baseline, only $10 \%$ knew that a girl could perform a breast self-exam compared to $54 \%$ at endline. The post-test showed that $99 \%$ of girls agreed that they could better manage their health after participating in Filles Éveillées.

Girls' knowledge of hygiene was measured through questions about the circumstances under which it is appropriate for a person to wash his or her hands. Knowledge was much higher than expected with $100 \%$ of the sample at baseline and endline reporting correct knowledge of the circumstances under which handwashing is appropriate.

\section{Sexual and Reproductive Health}

Based on findings from the formative research that girls in domestic service lack sexual and reproductive health knowledge and that employers and logeurs don't feel equipped to discuss this topic with girls, the Filles Éveillées program provided girls with information on sexual and reproductive health and where girls could access services in their communities. Knowledge on 
some items-such as knowing that a woman can get pregnant even after one unprotected sexual act, knowing that a person who looks healthy can be HIV positive, and knowing at least one way to avoid HIV-was higher than expected at baseline but still improved over time as shown in Table 2 and Figures 2 and 3. Likewise, favorable attitudes toward HIV testing were higher than expected on the pre-test but did increase from baseline to endline (73\% vs. 92\%).

TABLE 2: Percent distribution of surveyed girls in Filles Éveillées program by selected sexual and reproductive health knowledge items, by time of survey

\begin{tabular}{|l|l|l|}
\hline & Baseline (N=173) & Endline (N=129) \\
\hline $\begin{array}{l}\text { Knows when during the menstrual cycle a woman can get } \\
\text { pregnant }\end{array}$ & $1 \%$ & $35 \%$ \\
\hline $\begin{array}{l}\text { Knows that a woman can get pregnant even after one } \\
\text { unprotected sexual act }\end{array}$ & $55 \%$ & $78 \%$ \\
\hline $\begin{array}{l}\text { Knows that a person who looks to be in good health can be HIV } \\
\text { positive }\end{array}$ & $67 \%$ & $88 \%$ \\
\hline Number of correct ways named to avoid HIV & & \\
0 & $22 \%$ & $10 \%$ \\
1 & $62 \%$ & $48 \%$ \\
$2+$ & $16 \%$ & $42 \%$ \\
\hline
\end{tabular}

FIGURE 2: Percent distribution of surveyed girls in Filles Éveillées program by number of family planning methods identified, by time of survey

Baseline

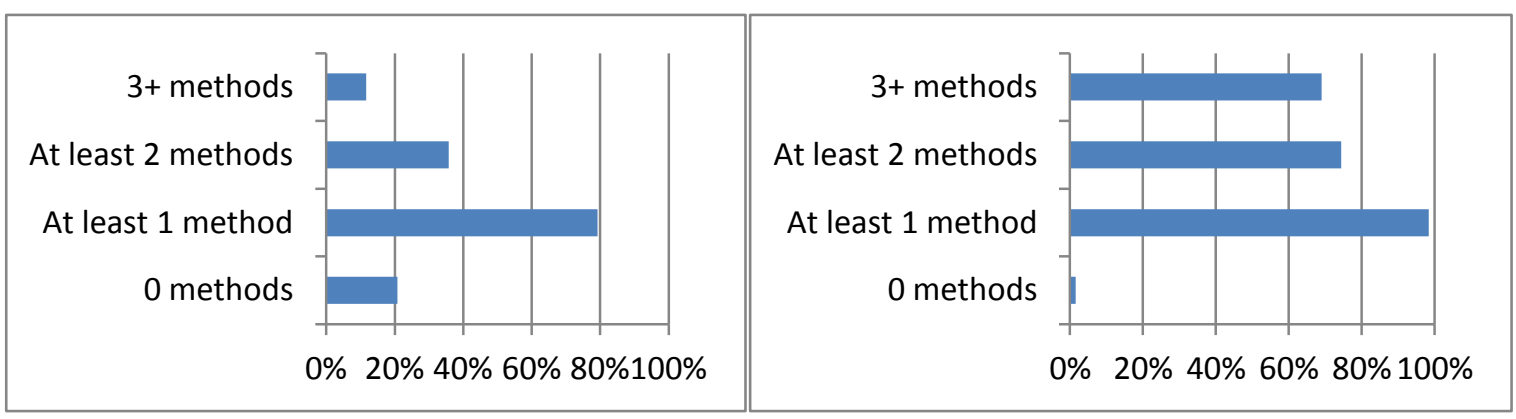

FIGURE 3: Percent distribution of surveyed girls in Filles Éveillées program by number of sexually transmitted infection symptoms identified, by time of survey

\section{Baseline}

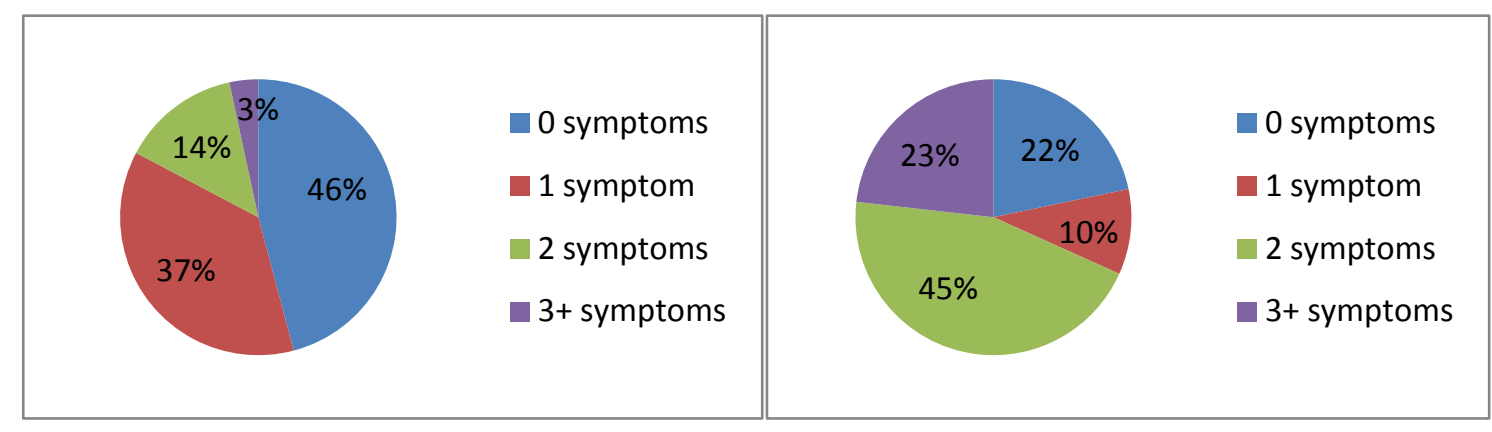

\section{Endline}


In addition to increasing knowledge, the program aimed to make girls aware of available health services in their neigborhoods. Knowledge of where to go in the community to seek HIV testing was high at baseline but improved from pre-test to post-test (88\% vs. 100\%). Awareness of at least one place in the community that provided family planning methods increased from $67 \%$ at baseline to $91 \%$ at endline. Knowledge of where to go within the community in the event of rape or harassment was less than one-fifth at baseline and improved to almost one-half at endline.

\section{Financial Capabilities}

Girls in domestic service are already economically active, and Filles Éveillées developed their capabilities in savings and budgeting and their ability to talk about money and plan for their financial futures. Despite the fact that more than half of these girls had never been to school before joining the program, they had higher than expected numeracy skills. Ninety percent of girls at baseline responded correctly to an addition question, likely due to the fact that they exchange money with vendors when shopping in the market for their employers.

Girls' reports of the principal items they spend their money on were consistent from baseline to endline and included things such as cosmetics, clothing, and sending remittances home to family. When asked who decides how she will spend her earnings, around two-thirds of the sample reported that she herself is in charge of such decisions, with a slight improvement from baseline to endline (65\% to $69 \%$ ). Girls at endline were more likely to report having a spending plan compared to girls at baseline (93\% vs. $81 \%$ ), likely owing to the financial capabilities session on this topic.

Savings behaviors improved from baseline to endline ( $81 \%$ to $90 \%)$, and at endline girls were more likely to report saving for emergencies and problems than at baseline (56\% vs. 43\%). Other notable reasons for savings included buying personal items and sending money to family members. Girls gave a variety of responses to where they keep their savings; of note, the percentage reporting that they kept their savings at home declined from $24 \%$ to $14 \%$ from baseline to endline, while the number saving in a bank or through a tontine went from $3 \%$ to $14 \%$. Ninety-nine percent of girls at endline agreed that the program had taught them how to save money.

Likewise, girls' reports of having savings goals improved from baseline to endline (46\% vs. $54 \%$ for short-term savings goals and $68 \%$ vs. $75 \%$ for long-term savings goals), with common shortterm goals of buying clothes and cosmetics and long-term goals of establishing one's trousseau and financial preparation for marriage. Girls' reported ability to talk with employers about money also improved from baseline to endline (49\% to $78 \%$ ).

\section{Gender}

Although this program was not designed to change gender attitudes or gender norms, the pretest and post-test assessed attitudes to see if participation in a girl-only, asset-building group had any indirect effects on gender attitudes over time. From pre-test to post-test, girls' attitudes became more gender equitable as shown in Table 3, though changes over time were less significant on some indicators than on others. For example, women needing to ask their 
husband's permission minimally changed from baseline to endline. Changes in ingrained gender views such as this require long-term interventions designed to work with multiple actors to change gender norms.

TABLE 3: Percent distribution of surveyed girls in Filles Éveillées program who agree with gender equitable statements, according to time of survey

\begin{tabular}{|l|l|l|}
\hline & Baseline (N=173) & Endline (N=129) \\
\hline $\begin{array}{l}\text { Boys should have to spend the same amount of time as } \\
\text { girls on household tasks }\end{array}$ & $22 \%$ & $40 \%$ \\
\hline Girls should be able to decide the person that they marry & $84 \%$ & $94 \%$ \\
\hline $\begin{array}{l}\text { Young people should be informed about family planning, } \\
\text { pregnancy, and childbirth before marrying }\end{array}$ & $89 \%$ & $99 \%$ \\
\hline Boys should be prioritized over girls in schooling & $54 \%$ & $43 \%$ \\
\hline $\begin{array}{l}\text { The husband should have the right to beat his wife if she } \\
\text { doesn't obey him }\end{array}$ & $58 \%$ & $31 \%$ \\
\hline $\begin{array}{l}\text { Women should always ask their husband's permission } \\
\text { before doing something }\end{array}$ & $95 \%$ & $92 \%$ \\
\hline
\end{tabular}

*Italicized statements are considered gender inequitable.

\section{DISCUSSION}

The Filles Éveillées program was developed to increase social networks and skill-building among migrant adolescent girls in domestic service in urban Burkina Faso. Although other programs exist for this population, Filles Éveillées is one of the first to build girls' health, social, and economic assets before something has gone wrong in their lives. Girls' support for the program was very positive, with $98 \%$ of girls at endline reporting that they thought more about their future now than they had before joining the program. Likewise, the entire endline sample said they would recommend Filles Éveillées to other girls like them.

The first cohort of this program demonstrated that despite their busy schedules, migrant adolescent girls are interested in the program and able to attend weekly sessions. Findings from the Cohort 1 pre-test and post-test showed measurable improvement at the level of the girl in all outcomes of interest: there was a decrease in the percent of girls who had never been to school (likely owing to the program's educational support for interested girls), a two-fold increase in the percent of girls who could read, increased social networks and safety nets for girls, improvements in girls' reports of self-confidence, improved knowledge of girls' ability to manage their own health, improved knowledge of sexual and reproductive health including HIV, increased awareness of health services available in their neighborhoods, improved savings behavior and 
increased savings goals, and greater support for gender equitable norms (though this was not an explicit goal of the program).

Notable improvement in girls was also seen in the interviewer's notes on the endline survey, which indicated that girls' knowledge acquisition was visible in their manner of responding to survey questions and offering valid responses to survey questions rather than selecting "don't know." Confidence, self-esteem, and social capital are all cornerstones of this program but can be hard to measure on standard surveys. Interviewer's notes indicate that, on the whole, girls at endline expressed themselves without embarrassment and with more confidence compared to baseline. Mentors and program officers from Association Tié had similar observations throughout the program and suggest that the program was effective in helping girls more freely express themselves and develop social networks. Given the importance of social capital and financial capabilities in helping vulnerable girls overcome challenges in their lives, the Population Council team decided to complement the baseline findings with qualitative data collection in these two specified domains. Qualitative data collection was completed in mid-2012, and findings have been summarized in a separate report.

As a pilot program, it is inevitable that Filles Éveillées would encounter obstacles in its first iteration. This first cohort allowed the opportunity to test the program model and data collection instruments in order to improve them. Having two serial cohorts in the program allows the research and program team time to test the program model and data collection instruments, reflect on cohort 1 findings, and make adjustments to the program before launching the second cohort. Quantitative findings and findings from the process evaluation (which has been written up in a separate report) revealed the need to refine the program design and implementation. For example, results show that girls' baseline knowledge of handwashing was already high; however, mentor notes from the program sessions reveal that girls knew little about dental hygiene. Therefore, the curriculum has been revised to devote less time to handwashing and has added a session on dental hygiene. Likewise, mentors' belief that the sexual and reproductive health section was too dense was taken into account and that module of the curriculum was accordingly revised. The revised curriculum includes simplified information on female and male reproductive systems, simplified questions to assess girls' capture of this information, more images, and additional stories about individual girls.

This study has several limitations. First, the study design is limited by not having a control group. Changes observed in participants between the pre-test and post-test could be due to factors outside of the control of Filles Éveillées. Future iterations of this program would benefit from a randomized control design, which would minimize threats to internal validity and allow for a stronger causal connection between provision of Filles Éveillées and observed outcomes.

Second, the program was designed to coincide with the dry season when migrant girls reportedly live and work in urban areas, and data collection was designed to take place just before program launch and just after program closure. However, the rainy season in 2012 started slightly earlier than normal, causing many girls to migrate to their villages of origin earlier than in other years. As a result, many program participants headed back to their villages before the official closure of the program and subsequent endline data collection. This unforeseen reality meant that the 
sample size for endline data collection was smaller than the baseline sample. The program could have suffered from selective attrition, and the endline sample could be biased toward those migrants who were better assimilated to urban life. The second cohort of this program from 2012-2013 will begin and end slightly earlier in an effort to retain as many participants as possible throughout the program duration and in order to minimize attrition before endline data collection.

Beyond the scope of evaluation in small-scale programs like Filles Éveillées, future research is needed to better understand the experiences of recently arrived migrant adolescent girls. More could be expected of demographic surveys, which have greater scope for inquiry, but neither of the major ongoing international survey programs-the Demographic and Health Surveys (DHS), sponsored by the US Agency for International Development, and the Multiple Indicator Cluster Surveys (MICS), sponsored by UNICEF-has ever made migration a data-collection priority. Indeed, the DHS has recently abandoned the two questions on migration that its surveys have asked for over 20 years, and the MICS program has never collected any migration information at all. Likewise, definitions of migration across surveys could be streamlined to provide more accurate assessments of the scope of migration to inform resource allocation. A person who migrated to a particular city from another place in the same major administrative region would certainly be counted as a migrant in the DHS, but might or might not be counted as one in a census depending on its treatment of within-region moves. Policymakers wishing to set adolescent girl programs on a solid base of evidence, using empirical data to inform decisions about the scale of the resources and the high-priority regions to which they should be targeted, will need to know that different messages may well emanate from different data sources. Recommendations for expanding the evidence base on migrant adolescent girls will be addressed in a forthcoming report on the target population. ${ }^{6}$

Findings from this evaluation demonstrate that it is possible to make measurable change in the lives of migrant adolescent girls in domestic service through targeted, evidence-based programs that build their social capital and help them develop health, social, and economic assets in a safe space under the guidance of a trusted female mentor.

\footnotetext{
${ }^{6}$ Temin, Miriam, Mark Montgomery, Sarah Engebretsen, and Kathryn M. Barker. Forthcoming. Girls On The Move: Adolescent Girls and Migration in the Developing World. A Girls Count Report. New York: Population Council.
} 